\title{
Research on the Evaluation Model of Cognitive and Behavior and the Influencing Factors Non-Language Factors
}

\author{
Yu Yuan \\ College of Foreign Languages China West Normal University, anchong, China \\ y_uan_yu@126.com
}

Keywords: Spoken English; Nonlinguistic factors; Impact factors; Evaluation model

\begin{abstract}
The final goal of English teaching is to make English learners correctly use English in their work, study and life, and they can express the English in the higher level. Nonlinguistic factors are the important influencing factors of the ability of spoken English, and they have great influence on the expression of spoken English. This paper is based on the nonlinguistic factors that have great influence on the comprehensive ability of spoken English to have a large number of practical investigation and experimental analysis, and it also constructs the evaluation model of the ability of spoken English that based on the nonlinguistic factors. It uses the theory of factor analysis to get the optimized training scheme, and its purpose is to provide reliable theoretical basis for the reform and innovation of teaching system of spoken English, and it also can exploit and innovate for the way of education.
\end{abstract}

\section{Introduction}

At the present stage, the researches of spoken English and the related fields are still in the rising stage of development in China[1]. For example, the exploration and educational reform countermeasures of nonlinguistic factors' influence on the ability of spoken English was written by Hua Zhu, and it was based on the importance of the ability of spoken English and the background of examination-oriented education, and it analyzed the irrational factors' influence on the cultivation of the ability of spoken English from many aspects, finally it put forward the corresponding teaching countermeasures to promote English teaching. Lihua Shen is the author of the discussion and countermeasures of the factors' influence on spoken English, and this article analyzed the factors' influence on the improvement of English learners' ability of spoken English from the factors of age, character, language environment, motivation and attitude. And at the same time it expounded a series of corresponding solutions. Research on the nonlinguistic factors' restraint of the output ability of college students' spoken English was written by Zhiqing Zhang and Dai Yu[2].

\section{Nonlinguistic factors' influence on comprehensive ability of spoken English}

The factors that have influence on the development of the ability of spoken English are complicated, and the effect of nonlinguistic factors on the improvement of the ability of spoken English should not be overlooked. The nonlinguistic factors that have influence on the ability of spoken English mainly include the learning motivation, language environment, inhibition of language anxiety, and lack of learning motivation. As shown in Figure 1, the four factors support the spoken English training together, and they play a very important role to improve ability of spoken English. The relationships of learning motivation, language environment, the inhibition of language anxiety and the lack of learning motivation are close, and they have mutual contain and influence, and each factor has important decisive character of other factors' transformation.

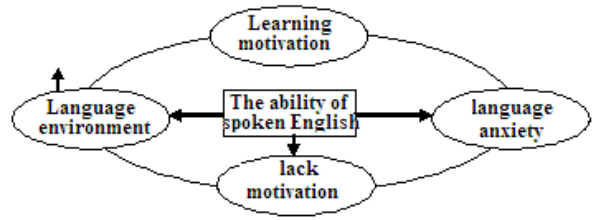

Fig 1. Correlation of nonlinguistic factors' influence on the ability of spoken English 
Learning Motivation .After 30 year's reform and opening up, the foreign language education in China has made significant progress and rich experience, but it never gets rid of the traditional mode of examination-oriented education. Most of the usage of the teaching method and the implementation of the education's policy still aim at the further studies[3]. This situation makes students' thinking and teacher's teaching method have limitation in the subjects that lack the diversity and innovation.

The lack of language environment. It can commonly use the spoken English to express the meaning and have long-term systematic training, and these are the important ways to improve the ability of spoken English. In the non-native speakers of English environment, it becomes the considerable obstacles to practice the spoken English[4].We find it difficult to use spoken English to express the meaning as the relaxed natural expression of mother tongue, and this is the objective facts that have influence on the improvement of the ability of spoken English. Under the influence of traditional concepts, most of the people are shy of using spoken English to express their meanings in the public, and they are afraid of the errors of grammar or words in the process of expression, even sometimes they may be thought to show off. So it is difficult to form the real, easy language environment, and it lacks the training opportunities, and it is difficult to improve spoken English.

Inhibition of Language Anxiety .Language anxiety refers to anxiety level of students in the process of using and learning English. The long-term lack of language environment will cause the student to produce timid psychology of the training of spoken English. This phenomenon is particularly prominent in the students that have poor English foundation and low self-confidence[5]. From the angle of psychology we can know that it is due to the negative emotional feedback of teachers and students, they produce deeper degree of psychological inhibition of practicing the spoken English, and they have strong self-protection awareness, and they almost don't participate in any spoken English practice. And many factors cause the psychological inhibition phenomenon.

Lack of Motive Force.The concept of spoken English teaching is the work centrality of English teachers, and it is the logic starting point of English teaching goal. Traditional teaching puts the students' test scores as the only basis of evaluating students' learning ability and level, and it is also used as the primary standard to measure the quality of teaching and teachers' teaching ability[6]. It is the malady of traditional education means to pay more attention to score than to the cultivation of the application ability of practice. It is the misleading area of traditional education idea to pay more attention to the knowledge in the books than to the intellectual inspiration. It is incorrect to understand the important points of English teaching and ignore the importance of spoken English training[7].And this is the important reason to make the English education not have motive force to improve the level of English.

\section{Research and analysis on evaluation model of nonlinguistic influencing factors of spoken English}

Foundational Model Analysis of Schema Theory of Nonlinguistic Influencing Factors .We can know that the concept of nonlinguistic factors' impact factors include two aspects, and they are the concept of nonlinguistic factors and the concept of impact factors of listening, speaking, reading, writing of the nonlinguistic factors. They are shown in Figure 2.

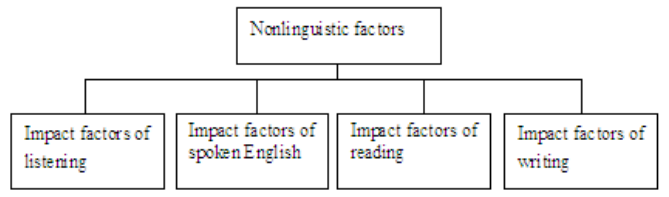

Fig 2. Structure of scheme model of nonlinguistic factors' concept

According to the structure of scheme model of nonlinguistic factors' concept in Figure 2, it further clarifies the multi-dimension and multi-level self-schema models that consist of nonlinguistic factors' concept, related exploratory countermeasures and confirmatory factor in the process of English learning.

Analysis and Research of Cognitive and Behavioral Model.According to the researches of the students' cognition and active learning behavior, it is based on the cognitive model of Clark and Wells 
and the cognitive behavioral theory of Rapee and Heimberg, and it can construct the cognitive-behavioral model of nonlinguistic factors that based on the training of spoken english. And they are shown in Figure 3.

In order to the further understanding and the promotion of students' learning initiative, it provides scientific and effective method of education improvement to encourage and guide students to carry on the training of spoken English. According to the above cognitive-behavioral model of nonlinguistic factors, it constructs the scientific and effective evaluation system of the ability of spoken English of nonlinguistic factors.

The value of the training environment of spoken English can be set as[8]:

$X=\{x(1), \cdots, x(n)\}$

The $\mathrm{x}$ is each nonlinguistic factor of evaluation system of the ability of spoken English. In the condition of $\mathrm{n}=7$, the evaluation standard of perception of system is[9]:

$\mathrm{Q}_{\mathrm{i}}=\sum_{j} v_{i j} x$

The $\{\mathrm{v}$ ij $\}$ is the learning cognitive factor, and a $(\mathrm{x})$ is the internal and external clue function of the system, and it takes the negative evaluation function, and there has[10]:

$\mathrm{a}(x)=\frac{1-e^{-x}}{1+e^{-x}}$

The result of the evaluation is: $\hat{\mathrm{y}}=\sum_{i} w_{i} \mathrm{O}_{i}$

Fig 3. Cognitive-behavioral model of nonlinguistic factors

The $\hat{y}_{\text {is }}$ the output variable of evaluation system of the ability of spoken English, and $\left\{w_{i}\right\}$ is the coefficient of nonlinguistic factors.

The evaluation standard function is[11]:

$E=\frac{[y-\hat{y}]^{2}}{2}=\frac{e^{2}}{2}$

The evaluation system can accurately get the main factors and the degree of their influence of nonlinguistic factors' influence on the ability of spoken English. The actual output y of the evaluation system is put as the positive feedback signal to ensure the reliability of the system, and it is compared with the evaluation output $\hat{\mathrm{y}}$ of nonlinguistic factors, at the same time it should make $\mathrm{E}<\varepsilon$ ( $\varepsilon$ is the minimum required coefficient of evaluation standard). If it can't meet the specified requirements, it should constantly adjust all kinds of the coefficients of the nonlinguistic factors, and in this way it can achieve the ideal teaching effects.

According to the calculation formula of teaching feedback factors, it can get the corresponding learning laws, and there has[12]:

$\Delta \mathrm{W}_{i}=-\eta \frac{\partial E}{\partial \omega_{i}}=\eta[y-\hat{y}] o_{i}$

$\Delta v_{i j}=\eta[y-\hat{y}] a^{1}\left(Q_{i}\right) W_{j} X$

The $\eta$ is the coefficient of correction rule of learning method, and $0<\eta_{<1}$. 
It uses the evaluation system of the ability of spoken English to have accurate calculation of nonlinguistic factors of learning the spoken English, and the usage of calculation formula of teaching feedback factor can sum up the scientific and effective learning laws, and it is based on this situation to make the reasonable innovation of teaching plan.

\section{Teaching countermeasures}

The students chronically and passively accept the knowledge, and they pay more attention to the books and ignore the practice. This makes the students' spoken English ability difficult to get ascension, and there appears a large number of "English writing expert" and "dumb English". According to the training methods of improving the ability of spoken English, it combines with the related data and conclusions of evaluation system of the ability of spoken English, and it puts forward analysis theory of nonlinguistic factors' positive impact factor of the ability of spoken English.

The influencing factors can be set as $\mathrm{x}_{1}, \mathrm{x}_{2}, \mathrm{x}_{3}, \cdots, \mathrm{x}_{p}$, and the initial value of each factor is 0 , and standard deviation is 1 , each factor can be expressed with the teaching strategy combination of $f_{1}, f_{2}, f_{3}, \cdots, f_{k}$, and there has[13]:

$\left\{\begin{array}{c}x_{1=a_{i k}} f_{1}+a_{12} f_{2}+\cdots a_{1 k} f_{k}+\varepsilon_{1} \\ x_{2=a_{2 k}} f_{1}+a_{22} f_{2}+\cdots a_{2 k} f_{k}+\varepsilon_{2} \\ x_{3=a_{3 i}} f_{1}+a_{32} f_{2}+\cdots a_{3 k} f_{k}+\varepsilon_{3} \\ \vdots \\ x_{p=a_{i 2}} f_{1}+a_{p 2} f_{2}+\cdots a_{p k} f_{k}+\varepsilon_{p}\end{array}\right.$

Nonlinguistic factors have interaction in the teaching environment, and they have continuous changes within a certain range, and they directly or indirectly limit the degree of the improvement of teaching methods. $a_{i j}(i=1,2, \cdots p, j=1,2, \cdots, k)$ is the limiting quantity of fluidization factor, and it is the limited scope of the first $\mathrm{i}$ influencing factor variable of the $\mathrm{j}$ factor. If $\mathrm{x}_{\mathrm{i}}$ is the vector of the $\mathrm{k}$ dimensional factor space, ${ }^{a_{i j}}$ is the projection of $x_{i}$ in the coordinates of $f_{j}$. $\varepsilon$ is the special factors, and it is the situation that the initial input conditions cannot be explained by the above strategy combination, and the mean value is 0 .

In order to have better understanding of the analytical significance of nonlinguistic influencing factors of the ability of spoken English, it can grasp the relationship between the various factors and initial conditions, and it has to understand the important degree of various factors' influence on teaching practice. It starts from the implementation of efficient quality education to construct the variable variance of quality education. The common degree of variable $\mathrm{x}_{\mathrm{i}}$ is defined as follows: $h_{i}^{2}=\sum_{j=1}^{k} a_{i j}^{2}$

The variable variance of quality education objectively expresses the nonlinguistic factors' degree of influence on the other teaching conditions, and it is an important indicator to evaluate the integrity of teaching. If the degree of the quality education's implementation is high, the students will have easier and more positive training environment of spoken English. It is through the related formula of the environment factor $f_{j}$ and teaching performance to calculate the value of degree coefficient ${ }^{2}{ }^{2}$ of students' subjective initiative, and there has[14]:

$$
s_{j}^{2}=\sum_{i=1}^{p} a_{i j}^{2}
$$

From the formula (10) it can be seen that environmental factor $f_{j}$ has a crucial role to play the students' subjective initiative. Therefore, the teachers should encourage students to carry on the training of spoken English to create the positive teaching environment. This can give full play to students' subjective initiative, and finally it can achieve the ideal teaching results of spoken English.

\section{Conclusions}


English is the most widely used and the most important communicative language in the world today. The role of spoken English of interpersonal interaction is self-evident. Therefore, it is the target of the contemporary youth to continuously improve the ability of spoken English, and it also puts forward higher requirements for the teaching of spoken English. With China's rising international status and the frequent thorough of foreign exchange, the communicative competence of spoken English has closer relationship with people's life and learning. The good communication ability of spoken English is the powerful weapon of communication and development, and it has the correct and rational knowledge to improve the ability of spoken English, and it looks for the optimization scheme that is suitable for their own development.

\section{References}

[1] Hua Zhu. Exploration and educational reform countermeasures of nonlinguistic factors' influence on the ability of spoken English .Journal of Liaoning education administrative institute, 2010(02):33-36.

[2] Lihua Shen. Discussion and countermeasures of the factors' influence on spoken English .Shazhou professional engineering journal, 2010(06):25-28.

[3] Zhiqing Zhang, Dai Yu. Research on the nonlinguistic factors' restraint of the output ability of college students' spoken English.Journal of Changsha university, 2011(05):49-51.

[4] Minshan Wang. Analysis and countermeasures of emotional factors' influence on the ability of spoken English .Journal of Shaoguan University, 2010(10):12-15.

[5] Jingyi Chen. Analysis on the nonlinguistic factors' influence of non-English major students' spoken English learning .Journal of Jixi university, 2011(07):47-50.

[6] Wensheng Wu. Self-schema research on foreign language anxiety of university students .Shanghai normal university, 2011(03):39-42.

[7] Xiaoyan Yang. Influence of nonlinguistic factors on the teaching of English . Journal of Gansu Lianhe university (social sciences), 2011(05):51-53.

[8] 8. Qingmei Zeng. The measures and ways of spoken English teaching of nonlinguistic factors .Journal of Yueyang vocational technical college, 2010(03):77-79.

[9] 9. Liping Che. Research on characteristics of contemporary college students' self-confidence .Southwest university, 2010(07):101-103.

[10] Jiamei Lu. Practical application of principle of psychology in the process of emotional teaching .Shanghai: Shanghai education press, 2011:11-13.

[11] Zhuanglin Hu. Courses in linguistics .Beijing University Press, 2011:44-46.

[12] Huang Guowen. Summary of discourse analysis.Hunan education press, 2010:27-30.

[13] Splosky, B.S ociolinguistics . Shanghai Foreign Language Press, 2010:81-83.

[14] Yule,G. Pragmatics. Shanghai Foreign Language Press, 2011:66-69. 